\title{
Penso (hegemonicamente), logo existo: reflexões acerca da pesquisa acadêmica no mestrado profissional em Educação da UEMS
}

\author{
I think (hegemonically), therefore I am: reflections on academic research in the \\ professional master degree in Education of UEMS
}

\author{
Ana Carolina Pereira de Souza ${ }^{1}$ \\ Kelly Queiroz dos Santos ${ }^{2}$ \\ Marcela dos Santos Ortiz ${ }^{3}$ \\ Marcos Antônio Bessa-Oliveira ${ }^{4}$
}

\section{Resumo}

O presente trabalho deseja apontar (re)verificações acerca da pesquisa Acadêmica em Educação. As (re)verificações serão feitas a partir de uma perspectiva descolonial e das experivivências das autoras em questão. As mulheres e autoras desta pesquisa são pesquisadoras de um Programa de Mestrado Profissional em Educação e trazem para esta pesquisa relatos de suas experiências como participantes/discentes do programa. No decorrer das disciplinas e da produção dos projetos de pesquisas, as autoras constataram algumas divergências acerca de como a pesquisa acadêmica está posta, em grande parte, com visada eurocêntrico-moderna. Pois, se pensarmos (hegemonicamente), logo existiremos. Neste sentido, a reflexão em questão objetiva apresentar a episteme descolonial de abordagem dos referidos projetos em desenvolvimento para realização de pesquisas em Educação que versem a partir das histórias locais nas quais esses projetos e pesquisadoras estão situados: no estado do Mato Grosso do Sul. Haja vista que a perspectiva moderna universal/homogeneizante ainda impera na maioria das Universidades. Esperamos com a reflexão epistêmica evidenciar que é preciso descolonizar o saber para contemplar a máxima descolonial também na Educação: ser, sentir para saber fazer sendo. Pois, pensamos porque sentimos. Logo, tendo em vista a perspectiva descolonial dos trabalhos das autoras juntamente com o do orientador de ambas, a perspectiva eurocêntrica, hegemônica e moderna que ainda impera na pesquisa acadêmica, não nos cabe. Para isso trazemos reflexões e experiências em diálogos com diversos autores que pensam de forma outra a pesquisa acadêmica, propondo a opção descolonial como possibilidade para mudanças da estrutura disciplinar moderna controladora das Uni-versidades.

\footnotetext{
${ }^{1}$ Mestranda em Educação, Universidade Estadual de Mato Grosso do Sul, Maracaju, Mato Grosso do Sul, Brasil, anabresolinps@gmail.com

${ }^{2}$ Mestranda em Educação, Universidade Estadual de Mato Grosso do Sul, Campo Grande, Mato Grosso do Sul, Brasil, kellyq.santos@gmail.com

${ }^{3}$ Mestranda em Educação, Universidade Estadual de Mato Grosso do Sul, Campo Grande, Mato Grosso do Sul, Brasil, marcelaortiz1@gmail.com

${ }^{4}$ Pós-doutorando em Estudos de Linguagens, Universidade Estadual de Mato Grosso do Sul, Campo Grande, Mato Grosso do Sul, Brasil, marcosbessa2001@ gmail.com
} 
Palavras-Chave: Pesquisa Acadêmica; Descolonial; Educação.

\begin{abstract}
The present work aims to point out (re)verifications about Academic research in Education. The (re)checks will be made from a decolonial perspective and from the experiences of the authors in question. The women and authors of this analysis are researchers in a Professional Master's degree Program in Education and bring to this research reports of their experiences as participants/students of the program. Throughout the disciplines and the production of research projects, the authors found some divergences about how academic research have, in large part, a Eurocentric-modern approach. For if we think (hegemonically), therefore, we exist. In this point, the reflection in question aims to present the decolonial episteme of approaching the previously stated projects in development for carrying out research in Education that deal with the local histories in which these projects and researchers are located: in the state of Mato Grosso do Sul. Bearing in mind the modern universal/homogenizing perspective still prevails in most Universities, we hope with the epistemic reflection to show that it is necessary to decolonize knowledge to contemplate the decolonial maxim also in Education: being, feeling to know how to do being. After all, we think because we feel. Therefore, in view of the decolonial perspective of the authors' works together with the supervisor of both, the Eurocentric, hegemonic and modern perspective that still prevails in academic research, is not up to us. For this, we bring reflections and experiences in dialogues with several authors who think academic research in a different way, proposing the decolonial option as a possibility for changes in the modern disciplinary structure that controls the Uni-versities.
\end{abstract}

Keywords: Academic Research; Decolonial; Education.

\title{
Introdução - (Re)verificando a pesquisa Acadêmica em Educação
}

Somos sujeitos latino-americanos, mas ainda demarcados por costumes impostos pelos europeus: homens brancos cristãos e, academicamente falando, pela inflexibilidade da ciência moderna. A modernidade desconsidera o negro, a mulher, o indígena, o crédulo de matrizes não cristãs e todo o sujeito subalterno que não fala uma língua "ocidental", que não é fálico e que, por esses e outros motivos criados pelo discurso de poder, não produzem conhecimento, e mais, não produzem conhecimento científico. Esses sujeitos apenas serão reconhecidos e legitimados se suas próprias pesquisas se atentarem e mantiver o padrão de rigidez que a ciência moderna impõe, ou melhor: se não pensar (hegemonicamente) não existiremos! Em outras palavras, ainda é bastante latente na pesquisa acadêmica a demarcação epistemológica 
moderna do que é científico; quem são os sujeitos pesquisadores e quais são as temáticas que devem ou não ser pesquisadas na academia. ${ }^{5}$ Romper com essa colonialidade do saber requer do/a sujeito-pesquisador/a a compreensão de uma prática de pesquisa outra, como proposto por Edgar Nolasco (2018, p. 11-12), que se constrói

[...] por meio da reflexão de base pós-colonial, ou pós-ocidental, ou simplesmente fronteiriça, como prefiro. [...]. E uma razão de base subalterna, ou fronteiriça, não passa, grosso modo, de uma prática, uma teorização, um exercício teórico-crítico por meio do qual tanto a teoria quanto a crítica empregadas devem engendrar, por mais contraditório que possa parecer, a própria prática posta em execução no ato de pensar.

A prática faz parte daquilo que produzimos no pensar, ser e fazer, e que, portanto, é impossível a dissociação entre sujeito-pesquisa, logo, entre corpo e mente. Ainda que este proceder como ato de pesquisa seja demarcado pela insistência acadêmica de que este distanciamento seja necessário (muitas vezes obrigatório), por exemplo, quando nos apresentam a escrita científica e que é logo explicitado que ao/a autor/a é necessário distanciar-se enquanto pesquisador/a de seu objeto e que, portanto, precisa apresentar uma escrita impessoal: por conseguinte, separando o (corpo) que sente da parte (cabeça) que pensa. Entretanto, um modo outro de pensar nos permite problematizar acerca desta dicotomia sujeito-pesquisa, semelhante à fragmentação de intelecto (mente) e físico (corpo), revelando um corpo cartesiano que se abstrai de seu contexto para produzir conhecimento. Como se aquele (corpo) decepado da cabeça fosse capaz apenas de andar, enquanto àquela (cabeça) seria possível pensar assentada em um "corpo" de mármore (pedestal) inanimado.

Até aqui falamos de uma situação na pesquisa acadêmica universitária que tem, quase sempre, para não generalizar, base epistemológica moderna eurocêntrica que privilegia determinado padrão de investigação, objetos específicos, metodologias predefinidas por abordagens teóricas que sejam estabelecidas por meio de correntes teóricas, igualmente, quase sempre com autoria de homens europeus e quando muito estadunidenses. Nesse tocante, uma

\footnotetext{
${ }^{5}$ Quando nos referimos à academia neste trabalho estamos prioritariamente pensando na Universidade. Mas é bom considerar que academia no pensamento ocidental também se refere à escola e igualmente a qualquer instituição estabelecida que conceda prêmios ou diplomas por meio de suas áreas do conhecimento específicos: gastronomia, cinema, ciência, literatura, música, química, biologia, medicina, arte, entre muitas outras.
} 
busca breve, por exemplo, aos Bancos de Teses e Dissertações brasileiros vê-se que, quando não se concentram na totalidade desse perfil cartesiano, o fazem, por meio de perspectivas que esse padrão endossa como válidas. Quer dizer: nas Áreas do conhecimento reconhecidas como "duras" nas Universidades brasileiras - comumente conhecidas como Exatas, Biológicas e as Agrárias - o fazer acadêmico-científico presa pela relação laboratorial produto-objeto-análise-resultados a fim de atendimento às demandas, quase sempre também, porque visam muito naturalmente estes aspectos, mercantis.

Evidentemente, tais assertivas não o deveriam ser, ao menos com categorias tão delimitadas (engessadas), prática da Área de conhecimento das Humanidades. Claramente não lidamos com produtos, existe, comumente, um corpo em todas as pesquisas que suplantam, ou ao menos o deveriam suplantar, a ideia de objeto: “[...] afinal uma pesquisa tem alma [...]" (NOLASCO, 2018, p. 19). Esses dois primeiros (corpo e objeto) não são passíveis de dissecações analíticas em laboratórios equipados com tubos e reagentes para ensaios químicos nas Humanas; igualmente aos resultados e intenções, corpos e impressões são passíveis de subjetivações por meio de teorias que se relacionam por aproximações com experiências parecidas em "universos" particulares. Logo, teorias, teóricos e resultados, para as Humanidades, evidentemente para as Artes e a Educação - disciplinas mais próximas das pesquisas aqui em reflexão - não são aplicáveis a fim de alcançar os mesmos resultados produtivos de atendimento aos mercados consumidores internos e internacionais de produtos. A primeira tarefa de uma formação do indivíduo "humano" deve o ser a de proporcioná-lo pensar sobre questões de ordem política, crítica, social e cultural.

A universidade foi e segue sendo uma instância fundamental da colonialidade do saber. A transformação na Europa das universidades medievais (Bolonha, Salamanca, Coimbra) em universidades renascentistas estendeu-se no século XVI às colônias hispânicas: a Universidade de Santo Domingo, no México, San Marcos, de Lima, no Peru, a Universidade de Córdoba, na Argentina. E a Harvard, nos Estados Unidos, no século XVII. Enquanto Portugal não incentivou a criação de universidades, a Espanha se autoassinalou uma missão teopolítica: o controle dos corpos mediante o controle das almas, ou seja, das subjetividades. No século XVIII, a universidade renascentista mutou-se, na Europa, na universidade kantiana-humboldtiana. Esse modelo de universidade desloca a universidade teológico-humanista dos Estados monárquicos e nasce a universidade dos Estados seculares: a ideia de cidadania e democracia conecta o controle do conhecimento ao controle da autoridade. Na América, as universidades coloniais teológico-monárquicas 
mutam-se em universidades seculares estatais. E se fundam outras universidades, como a do Chile, em 1862, e a UBA, em 1821. Tudo isto antes que a França e a Inglaterra colonizassem a África e a Ásia, e começasse aí a instalação de universidades kantianas-humboldtianas. Enfim, a universidade e o museu são duas instituições chaves sobre as quais se fundou e se mantém a colonialidade do saber e da subjetividade (MIGNOLO, apud LORCA, 2014, p. 1-2). (Grifos do texto).

Nesse sentido, ao priorizarmos, de modo evidente, a necessidade de uma base epistemológica outra, que não se inscreva como mais do mesmo ou que simplesmente rompa com o antecessor na intenção de revisão do que está posto, como foi a proposta pós-moderna, ressaltamos que as argumentações epistêmico-modernas de ontologia de ser e tempo heideggeriana, da fenomenologia hegeliana ou ainda da noção de "fé nacional" kantiana não nos servem para argumentar a favor das falas de corpos que nunca tiveram voz ou vez. Igualmente não nos será base secular a perspectiva materialista que enxerga no corpo a relação limitada deste inscrita ao trabalho sem ressaltar, por exemplo, que corpo e trabalho também estão sob a classificação de gênero, raça e classe históricos (QUIJANO, 2019). Portanto, evidentemente ainda deve ficar claro que não se trata de mais uma vez dar voz e vez para quem não fala ou que não pode se colocar, menos ainda o será de permissividade a algum sujeito desconsiderado/exteriorizado pelos pensamentos moderno europeu erigido no século XVI e/ou estadunidense pós-moderno após o século XIX.

Quando um sistema pedagógico, "vaca sagrada", como o chamou Illich, se identifica com a própria divindade, a verdade absoluta, a ideologia acaba reinando sobre os mesmos que são ocultados e interpretados como nada, bárbaros: "O ser é, eu sou o ser; o não-ser não é: a periferia, as classes oprimidas, o pobre, o outro não é", é a própria sacralização do fetichismo pedagógico. Parmênides foi seu primeiro grande sacerdote, Rousseau, o maior dos europeus, e os Dewey são seus acólitos.

Negar a divindade do sistema fetichizado é o autêntico ateísmo. É a negação da negação, [...]. O antifetichismo é um saber orientar as coisas para seu devido lugar, para a verdade. A questão não é dizer - com Hegel ou Nietzsche -: "Deus morreu!" A questão é: Qual o Deus que morreu? O fetiche? (DUSSEL, 1982, 104). 
$\mathrm{Na}$ razão de base subalterna, a teoria está a trabalho da teorização fronteiriça, e não o contrário, que é o que costuma ser feito dentro das atuais Uni-versidades. A academia prioriza ainda, mesmo nas Humanidades, caso muito particular da Educação, uma prática de relação laboratorial produto/objeto-análise-teorias concretas-resultados que está desvinculada dos corpos dos sujeitos das pesquisas tanto quanto dos sujeitos/sujeitas pesquisadores/pesquisadoras. Logo, no Ocidente só pensamos determinado objeto a partir de conceitos e teorias já estabelecidos que podem, em alguns casos, excluir o objeto que não se encaixa à essas teorias, portanto, só podemos pensar hegemonicamente sobre (por cima) de produtos/objetos que podem ser analisados (dissecados), por meio de uma teoria internalizada que apresente resultados qualitativos escamoteados de quantitativos concretos. Mas desejamos aqui e no desenvolvimento de nossas pesquisas na pós-graduação junto ao nosso Programa apresentar modos outros de pensar e produzir arte, cultura, ciência e conhecimento. Pois, ambos, corpo-pesquisa e pesquisa-corpo fazem-se presentes o tempo todo em nossos projetos. Assim, buscamos o descontrole dos corpos mediante ao autocontrole das nossas subjetividades.

\section{A pesquisa Acadêmica por uma perspectiva outra}

Uma pesquisa de base epistemológica descolonial, contrariando a lógica moderna de investigação, não se acerca da ciência cartesiana como parâmetro primeiro para constituição desta. Logo, pensando desta não opção pela "razão moderna", considerando nossa opção (de vida) pela descolonialidade da acadêmica, por conseguinte das pesquisas, do trabalho docente e da formação docente, somente podemos constituir pesquisa por meio de uma argumentação outra que passe pelos próprios corpos do sujeito-pesquisador-que-é-também-seu-objeto ou abordando objetos-que-fazem-parte-dos-corpos-dos-pesquisadores. Quer dizer, por meio de uma abordagem epistemológica crítico biogeográfica fronteiriça (BESSA-OLIVEIRA, 2020) edificamos um pensar que está inscrito no corpo dos sujeitos (bios) que estão situados em lugar geográfico específico (geo) e que, por sua vez, produzem narrativas (gráfica/grafias) que não passam estritamente pelo crivo avaliativo da ciência moderna cartesiana. Logo, sentimos e por isso existimos também enquanto objeto-pesquisas! 
Pensar descolonialmente significa desatrelar-se dos pressupostos da epistemologia moderna baseados na diferença entre sujeito cognoscente e objeto a conhecer. Quando, nas propostas de tese se lê "meu objeto de estudo é X" e "meu método é Z", sabemos que estamos em plena colonialidade do saber. Mas, sem dúvida, é mais do que isto. A descolonialidade são os processos de busca de se estar no mundo e fazer nesse estar (kuscheanamente dito), desobedecendo àquilo que a retórica da modernidade e do desenvolvimento quer que sejamos e façamos (MIGNOLO, apud LORCA, 2014, p. 3) (Grifos nossos).

Por conseguinte, estas pesquisas como as nossas que se inscrevem em corpos (vivos) só podem ter narrativas, tanto nelas próprias quanto nesta reflexão de caráter situacional das "perspectivas teóricas e metodológicas de formação de professores nos contextos dos mestrados profissionais em educação", em nosso caso particular acerca do PROFEDUC/UEMS, de perspectiva biográfica e que, por isso, às vezes, para aqueles leitores que prezam pelas abordagens tradicionais, parecem ter caráter de senso comum. Mas, entretanto, o que seria do senso científico moderno se não existisse o que chamam de senso comum? Neste caso, portanto, elegemos como opção a produção de conhecimentos de modo comum, quase como uma conversa, como também ressalta Walter Mignolo em Histórias locais/Projetos globais (2003) quando, logo na introdução àquele livro, garante ter constituído parte de todo o conteúdo do livro por meio de conversas com pessoas de senso comum. Haja vista que a ciência, para o pesquisador descolonial, não o serviria graças as suas bases epistemológicas modernas: homem, branco, de classe alta, cristão, falante de uma das línguas oficiais.

Para isso, para não incorrer no discurso moderno, nas produções enraizadas no saber ocidental, uma das possibilidades será se valer de práticas outras como caminho "de desobedecer epistêmica e conceitualmente aqueles conceitos modernos que já se cristalizaram no discurso aquilatado sob a rubrica de pensamento moderno que circula sobretudo dentro da academia e das disciplinas institucionalizadas" (NOLASCO, 2018, p. 12). Em nossas experiências enquanto acadêmicas foi notório como o pensamento moderno está ainda muito enraizado, ou melhor, petrificado na Academia por meio de seus/suas professores/as em suas disciplinas acadêmicas. Em alguns momentos no discurso academicista é possível entrever 
pensamentos aparentemente outros, mas na prática, ainda são, em grande parte, direcionados pelo saber moderno. Neste caso, portanto, não há sequer saber científico que ilustre esses processos por meio de citações recheadas de paráfrases e metáforas, comumente usadas pelos pensamentos moderno e pós-moderno: é preciso um discurso narrativo de quem sente no corpo a emergência de enormes fronteiras entre o que seria o conhecimento científico e os deformados por aqueles como saberes de senso comum.

Há casos, por exemplo, em que o professor da disciplina apenas discorda de uma referenciação teórica que não seja a sua. Mas, fazendo preponderar a soberania de lugar de fala de docente (indecente) e do pensamento hegemônico moderno (agigantado pelas ideias de classificação por raça, classe e gênero soberanos), alguns "mestres" reduzem e desqualificam o desconhecido. Haja vista que, falando do seu pedestal de mármore, uma cabeça que parece pensar fora do corpo, alguns docentes preferem desconhecer os discursos não matemáticos, não filosóficos, não sociológicos, entre outros, que não são moderno-disciplinares como aqueles como saberes/conhecimentos com receio de perder suas bases de sustentação frias e descorporificadas.

A pesquisa pautada em uma perspectiva descolonial é uma forma subalterna de pensar outra e não mais uma forma de pensar das que são feitas nas Academias. Mas uma forma subalterna de pensar outra não é compreendida, respeitada ou até mesmo considerada pelo saber moderno disciplinar. A perspectiva de base subalterna e uma opção de vida! Mas, entretanto, quais vidas prezam dentro das acadêmicas? Em verdade, é a mais questionada, perseguida, contrariada e marginalizada. Para trazer a forma descolonial de pensar, pesquisar e produzir conhecimento, igualmente por meio da arte, da ciência e da cultura sem hierarquias é preciso resistência. É preciso desobediência à lógica cartesiana de produção de conhecimento até aqui imperante na grande maioria das Uni-versidades. O problema não está em o ouvinte não entender a perspectiva, mas no desconsiderar ou reprovar saberes outros por que não se enquadram nas formas já estabelecidas de pensar, pesquisar e produzir conhecimento, ou seja, não é um modelo hegemônico, moderno e consequentemente excludente de base cientificista.

O problema também está no desconhecimento de opções outras que não sejam aquelas as quais o docente está comumente habituado a reproduzir como seu único ato de ensinar, analisar, metodologizar, teorizar e praticar educação nas academias. O corpo docente e muitas vezes o corpo discente não estão abertos à novidades que não tenham migrado da Europa ou 
dos Estados Unidos. Haja vista que, em alguns casos, a descolonialidade como opção é taxada de vitimização ou de insubmissão aos mandos e desmandos acadêmicos da modernidade inter- sala de aula. Mas, “[...] a descolonização não é uma questão de políticas estatais. Os Estados estão atrelados às corporações e aos bancos. A administração universitária pode apoiar, em certos momentos, algumas iniciativas, mas não lhe é possível iniciar estes projetos.” (MIGNOLO, apud LORCA, 2014, p. 3). Primeiro porque esses projetos estão emergindo de corpos das diferenças coloniais. Em segundo lugar porque, até hoje, quem ocupa os lugares nas Uni-versidades que não são pluriversais, na sua grande maioria, são homens, brancos, de classe alta, cristãos, falante de uma das línguas oficiais e defensores da ciência cartesiana. Portanto, os indígenas, negros e mulheres que chegam lá devem no mínimo se enquadrar sendo submissos ou se reconheçam como oportunizados.

O mais agravante deste modo hegemônico de produção (ciência) é que nela é embutida a legitimidade para a construção de conhecimentos e aos outros sujeitos e suas contribuições são atribuídas o conceito de sabedoria desqualificada, que aqui indicaria sinônimo de 'senso comum'. Este é invalidado cientificamente ou, como ainda foi-nos imputado no discurso de um dos professores da disciplina obrigatória dentro do programa PROFEDUC, colocado como saberes "destruidores de casas com pilares sólidos, válidos e universais que ficam na chuva sem saber o que fazer ou para onde ir": o conceito de casa aqui foi utilizado como metáfora para formas outras de produção de conhecimento que não ocupam os lugares palacianos edificados pela ciência.

Logo, metáforas como essas demonstram a importância da emergência de perspectivas outras dentro das academias para mostrar que não só precisamos conhecer as "casas" já construídas e demarcadas pela lógica eurocêntrica. Nós somos obrigados/as a vivenciá-las. Prova disso são as aprovações nas disciplinas obrigatórias, pois precisamos, na maioria das vezes, inscrever nossos objetos sob este modo moderno de produção de conhecimentos. Mas a questão relevante, a saber, é que ao apresentarmos este modo outro de fazer/produzir conhecimento, ou na metáfora empregada, estabelecer nossas/novas "casas", não pretendemos desconstruí-las ou mesmo conserta-las sob o viés moderno de ciências, mas sim (re)verificálas e construir modos outros de produção de saber/conhecimento que contemplem o desconsiderado pela sapiência moderna. 
Assim, estudantes e docentes ainda são tomados/domados como corpos que "sofrem" com políticas de corpos engessados no ensino de Arte e, do mesmo jeito, esses mesmos professores ainda são formados a partir de teorias estruturais que controlam suas ações em sala de aula, promovendo, assim, o contrário às possibilidades de os corpos poderem-ser corpos em política nas escolas.

Conquanto, aqueles corpos são enquadrados aos currículos acadêmicos disciplinares (nas escolas ou nas Universidades de bases modernas) estabelecidos pelas regras, pelas leis e pelos poderes, estatais e privados, e que estabelecem que os indivíduos devam aprender em função da atenção ao mercado de trabalho para o consumo como únicas formas de continuar a viver em sociedade. (BESSA-OLIVEIRA, 2019, p. 109-110). (Grifos do texto)

Podemos pontuar que a concepção errônea sobre nossa base epistemológica de pensamento descolonial ocorre porque ela se materializa e se estabelece para além dos pilares da modernidade, isto é, do positivismo, da fenomenologia e do marxismo o que corrobora para que haja constantes ocultações, marginalizações e silenciamentos sobre esse modo outro de conhecimentos/saberes. O pensamento descolonial como opção outra (de vida e de pesquisa) requer compreender que nem a ontologia ou a fenomenologia que são descorporificadas nos contemplam, já que "A ontologia é fenomenologia; é o logos ou pensamento acerca daquilo que aparece (o fenômeno, o ente) desde o fundamento (o ser)" (DUSSEL, 1982, p. 64), e que nem tão somente o trabalho marxista pode ser a razão de contemplação de corpos que não viveram a experiência eurocêntrica/estadunidense. A base do pensamento descolonial como opção é uma lógica outra em relação ao advento da modernidade/pós-modernidade, do comunismo/capitalismo como únicas alternativas.

Percebemos essa concepção contestável quando a perspectiva descolonial não é apresentada em disciplinas na Academia, somente o positivismo, a fenomenologia e o marxismo. Em discurso também nos é apresentada a perspectiva pós-moderna, mas esta não nos foi possibilidade para desenvolvimento de um artigo final nessas mesmas disciplinas. Então, claramente os demais colegas da turma de pós-graduação na Academia, que não conhecem por outras vias a perspectiva descolonial, como nós conhecemos pelo nosso orientador, terão dificuldades durante a leitura de um projeto de pesquisa que tenha esta episteme como perspectiva, chegando a "não entender nadinha", porque lhes são negados tais conhecimentos. 
A emergência primeira de partir de uma noção de Estudos de Culturas, [evidencia das epistemologias descoloniais] não mais apenas Estudos Culturais, coaduna, por exemplo, com a necessidade de ressignificar as culturas que sempre foram negadas (SANTOMÉ, 1995) ou desconsideradas, e até hoje ainda o são, especialmente nos currículos escolares [e universitários]. (BESSA-OLIVEIRA, 2019, p. 122). (Grifos do texto).

Não queremos com esta informação dizer que todos os projetos de pesquisas deveriam partir da perspectiva descolonial, o que Boaventura de Sousa Santos chama de epistemicídio (1999). Apenas percebemos, inclusive na fala de colegas da turma de pós-graduação durante as apresentações de nossos projetos de pesquisas, que a perspectiva descolonial também deveria ser apresentada como possibilidade, mesmo que não escolhida pelos demais orientadores/docentes, mas que seja apresentada como caminho/opção de pesquisa, inclusive para auxiliar na leitura dos projetos que fazem uma escolha descolonial. Querendo ou não a academia e seus "fieis defensores", a descolonialidade é e permanecerá sendo uma visão e uma orientação entre outras coexistentes nas Uni-versidades a fim de promover a pluriversidade de saberes em contato como também defendeu Boaventura de Sousa Santos. Haja vista que a convivência entre saberes permitirá inclusive a ciência ter o direito de permanecer existente como opção. Ou seja, a universidade deveria ser "sem condição", como propõe Derrida:

Em primeiro lugar, Derrida escreve que a universidade moderna, aquela cujo modelo europeu tem-se tornado predominante há dois séculos nos Estados de tipo democrático, deveria ser uma universidade sem condição. Dita universidade exige, e se lhe deveria reconhecer, para além da liberdade acadêmica, uma liberdade incondicional de questionamentos e de proposição e, inclusive, o direito de dizer publicamente tudo o que lhe sugerem uma pesquisa, um saber e um pensamento da verdade (SKLIAR, 2005, p. 30). (Grifos do texto).

Não queremos também propor a descolonialidade como verdadeira e única possibilidade, ou que esta supere as já existentes, mas refere-se a uma outra opção investigativa que a academia desconhece. E que vários dentro das academias preferem 


\section{QO DEVIR EDUCAÇÃO}

ISSN: 2526-849X

continuar desconhecendo. Conforme Walter Mignolo (2017, p. 15), sendo uma opção “o decolonial abre um novo modo de pensar que se desvincula das cronologias construídas pelas novas epistemes ou paradigmas (moderno, pós-moderno, altermoderno, ciência newtoniana, teoria quântica, teoria da relatividade etc.)”.

Essencialmente é com o fazer descolonial que se desprende do conhecimento imperial/moderno e da matriz que este poder colonial estabelece. Walter Mignolo (2010) chega a mencionar o crível que diz que o que é produzido por sujeitos-europeus é científico e o que é produzido por outros é sabedoria, hierarquizando conhecimentos e sentenciando "às margens", ao periférico os diferentes saberes taxados de senso comum. É relevante dizer que para isso o sujeito deve então ser percebido como ser que interage com o mundo desde o início de sua existência, que inserido em uma determinada cultura estabelece relações e constrói sua identidade, personalidade e fundamentalmente sua forma de visualizar, interpretar e principalmente (re)significar os fatos de seu cotidiano e o que está posto ao seu redor.

Nesse sentido, não basta empregar conceitos advindos de teorização fronteiriça, ou mesmo nomes e sobrenomes de pensadores desse pensamento, entendendo que, agindo assim, estaria pensando descolonialmente. Nada disso. É, mais do que preciso, é necessário a inscrição do corpo e do compromisso teórico, político mesmo desse pesquisador. E tal presença se daria por meio da inscrição de seu bios e de seu lócus ancorando seu lócus enunciativo, mais sua consciência fronteiriça, ou condição mesma de pensar (NOLASCO, 2018, p. 12-13).

É necessário trazer o corpo para a pesquisa, trazer nosso corpo, pois nele está inscrita toda a nossa história e ser. Nosso corpo que diz quem somos, que produz arte, ciência, cultura e conhecimento. Podemos até nos arriscar a dizer que é humanamente impossível não ter a inclusão de nosso corpo na pesquisa, pois é ele quem pensa, quem escreve, quem reflete, mãos que digitam, corpo que sente e vive todo o processo de produção. Boaventura de Sousa Santos fará uma reflexão extremamente pertinente ao que temos pensado e proposto aqui:

Apesar do fato de pensarmos e conhecermos com o corpo, apesar de ser com o corpo que temos percepção, experiência e memória do mundo, ele é 
tendencialmente visto como um mero suporte ou tábula rasa de todas as coisas valiosas produzidas pelos seres humanos. Isso é especialmente verdade no que se refere ao conhecimento eurocêntrico, científico ou não, devido aos pressupostos judaico-cristãos que lhe são subjacentes, impregnados da distinção absoluta entre corpo e alma. O corpo de emoções e afetos, do sabor, do cheiro, do tato, da audição e da visão não está incluído na narrativa epistemológica, mesmo depois de Spinoza ter criticado definitivamente essa exclusão como irracional e estúpida (SANTOS, 2019, p. 137).

Enfatizamos uma vez mais a importância de pensar e produzir conhecimento, arte, ciência e cultura como sujeitos biogeográficos (BESSA-OLIVEIRA, 2020), como Nolasco (2018, p. 13) diz que "Logo, pesquisar a partir de onde se pensa faz toda a diferença para aquele pesquisador que sabe, sente e pensa que a inserção de seu bios na origem de sua reflexão crítica faz toda a diferença".

A reinserção do bios dentro da discussão do pesquisador, a começar por seu projeto de pesquisa e por sua atitude e compromisso com seu lugar de estudo ou trabalho, não mais seria do que a presença inconteste do corpo vivo do sujeito e do "objeto de pesquisa" que, na verdade, nunca saíram de cena da pesquisa, como tentou nos fazer crer o modelo acadêmico institucionalizado moderno (NOLASCO, 2018, p. 13-14).

Por que existem ainda dificuldades em compreender a inscrição do sujeito na pesquisa? E aqui falamos de nós mesmas que em vários momentos acabamos "aprisionadas" pela teorização e conceitos já existentes e acabamos como autoras nos esquecendo de fazer nossa inscrição enquanto pesquisadora-docente e de relacionar assim práticas e modos de ser, sentir e saber. Isso ocorre porque alguém diz que é preciso separar objeto e sujeito. E esse alguém é a epistemologia moderna que via travestimentos docentes na academia replicam discursos. Está presente na epistemologia moderna "o modo teórico de pensar moderno que sempre separou sujeito e objeto, dando a este o estatuto indiscutível de objeto que não pensa, amorfo, inferior, desprovido de teoria, com o objetivo claro de assim dominá-lo, de o por sub judice a uma teoria pensante" (NOLASCO, 2018, p. 17).

Por conseguinte, contra essa lógica abstrata da ciência moderna, contra o espaço vazio da física de Newton, ou o espaço existencial da fenomenologia, "tais espaços são ingênuos 
irreais, não conflitivos. O espaço de um mundo dentro de um horizonte ontológico é espaço do centro, do estado orgânico e auto-consciente sem contradições porque é o estado imperial" (DUSSEL, 1982, p. 8), fazemos emergir, por meio de nossas pesquisas de base epistêmica descolonial, um lugar ocupado por corpos da exterioridade cheios de experivivências que a Matemática, a Física, a Química ou a Educação de corpos amorfos - de corpos-mortos nunca lograrão compreender graças aos seus docentes que são, de certa forma, cabeças-semcorpos.

\section{Experivivências outras de mulheres na pesquisa acadêmica}

Para nós que estamos na Academia e desejamos fazer algo diferente do que já está posto e é reproduzido pela maioria, uma pesquisa científica que tem como teorização a perspectiva descolonial, existe uma saída. Para Edgar Nolasco (2018, p. 17), para nos livrarmos do cientificismo moderno e seus fantasmas, a saída "é aprender a desprender-se das amarras das opções teóricas, estéticas, políticas, conceituais, culturais, filosóficas impostas enquanto 'outro' da exterioridade”. Não existe uma história da filosofia, por exemplo, segundo Enrique Dussel (1986), existem histórias de filósofos que devem, por conseguinte, retratar histórias de povos que não foram descobertos, mas que foram "en-cobertos" (DUSSEL, 1982) pela sapiência moderna.

O desafio descolonial é se desprender "do modelo ou referencial teórico [que como] um modelo euro-norte-americano que ao ser pensado no centro (Norte) simplesmente ignorou a produção epistemológica da fronteira (Sul)" (NOLASCO, 2018, p. 18). Dentro de uma perspectiva cartesiana, que conta com objeto, hipótese, metodologia, análise e resultado, o corpo foi excluído, desconsiderado e isso reverbera nas pesquisas acadêmicas até hoje. Não se está interessado nas impressões do corpo-pesquisador, que reverbera seu ser, sentir e saber enquanto pesquisador biogeoistórico. Na Academia insistem em dizer que é preciso fazer uma separação entre objeto e o sujeito, pois o corpo do sujeito, o bios, não deve fazer parte da pesquisa (a cabeça): é preciso distanciar-se para analisar, não sentir. Como se fosse possível fazer tal separação. 
Como se a pesquisa fosse uma entidade que emerge sozinha do mundo dos mortos, professores catedráticos inferiorizam aos discentes alegando que seus trabalhos são poéticos demais ou que simplesmente não é ciência. Exatamente porque as pesquisas descoloniais apresentam o corpo vivo, o que deveria ser o ponto crucial para as pesquisas em Educação, os projetos são rechaçados por supostos intelectuais jurássicos que veem no corpo da exterioridade uma inferioridade atribuída pela presença inconteste do pensamento da modernidade. Pior ainda, supostamente ressaltando a ciência da abstração como a única capaz de produzir uma construção de conhecimento que lhe escapa diante da sua imposição autoritária muitas vezes machista, branca e preconceituosa.

Nós [homens e mulheres], anthropos ("os outros e as outras"), que habitamos e pensamos nas fronteiras com a consciência descolonial, agimos em processos de desprendimento, de re-existência; e, para desprendermos, precisamos ser epistemologicamente desobedientes. Pagaremos o preço, uma vez que periódicos e revistas, as disciplinas das ciências sociais e humanas (especialmente as indexadas que funcionam como patrulhas nas fronteiras para evitar a passagem dos ilegais), assim como as escolas profissionais, são territoriais. Em outras palavras, o pensamento de fronteira é a condição necessária para pensar descolonialmente. E quando nós [homens e mulheres], anthropos, escrevemos nas modernas línguas ocidentais e imperiais (espanhol, inglês, francês, alemão, português ou italiano), fazemos isso com nossos corpos na fronteira. (MIGNOLO, 2015, p. 180-181. (Tradução livre nossa).

A pesquisa descolonial vai para um lugar oposto a este do pensamento cartesiano, portanto não estamos presos ao objeto, hipóteses, metodologia, análise e resultados que limitam, fecham e desconsideram-nos. Falamos de um lócus no qual estamos inscritas, nosso bios é extremamente essencial em nossa pesquisa. Consideramos nosso corpo como produtor de arte, cultura, ciência e conhecimento, consideramos nossas experivivências também como saberes na esteira de Boaventura Santos acerca da ecologia de saberes. Somos pesquisadoras com especificidades biogeoistóricas e produzimos arte, cultura, conhecimento e ciência a partir disso.

Como afirma Nolasco (2018, p. 19), "Nosso corpo também faz parte da epistemologia da qual nos valemos para pensar e nos pensar. $\mathrm{O}$ bios se inscreve nesse lócus enunciativo por 
meio de um discurso histórico que antecede a tudo. Precisamos aprender a falar do bios e do corpo; afinal uma pesquisa tem alma". Ninguém, nenhum pesquisador trata do fora, seu corpo sempre é lançado sobre suas pesquisas e produções.

Por isso, por nos encontrarmos mais além da totalidade européia, moderna e dominadora, é uma filosofia do futuro, é mundial, pós-moderna, de libertação. É a quarta idade da filosofia e a primeira idade antropo-lógica: deixamos para trás a fisio-logia grega, a teo-logia medieval, a logo-logia moderna, assumindo-as, porém, numa realidade que a todas explica (DUSSEL, 1986, p. 213).

Como forma de desobedecer epistemicamente, como modos de ser, sentir e saber outros trazemos brevemente nossas pesquisas que emergem de nós enquanto sujeitas biogeoistóricas, que emergem de nossos corpos, pesquisas que estão inscritas na Academia, ainda nesses padrões discutidos e apresentados até então no decorrer deste trabalho. ${ }^{6}$

Uma das pesquisas deseja apresentar o ensino da cultura sul-mato-grossense por meio dos saberes culturais (educação, arte e gastronomia), a partir de uma proposta epistemológica outra: Arte-Educação Descolonial, pensando uma forma outra de se falar em arte, educação e gastronomia que vai além daquilo que o pensamento europeu impõe; que arte se resume em bagunça, educação só é válida se estiver ancorada na lógica cartesiana e de que gastronomia só serve para matar a fome.

A pesquisa da segunda autora trata de um olhar outro para os conceitos de Arte, Cultura, Conhecimento e Mediação Cultural, assim como a (re)verificação de como está posta a relação entre estudante, professor, conteúdo e contexto escolar no ensino de Arte. Feitas tais (re)verificações, a pesquisa deseja desenvolver a proposta de Arte-mediação que visa aproximar os sujeitos sociais do ensino de Arte (estudante, professor, conteúdo e contexto escolar), indo além da proposta da mediação que visa aproximar o público dos artistas e de

\footnotetext{
${ }^{6}$ É no mínimo curiosa a grafia "sujeitas" aqui colocada, vão rapidamente, no ímpeto da modernidade linguística, argumentar que é uma grafia errada na menos pior das hipóteses. Entretanto, sabendo que, na grande maioria das vezes, impera um saber moderno disciplinar na língua também, preferimos por explicar a incursão do termo no gênero feminino a fim de lembrar que o trabalho tem autoria feminina de três pesquisadoras. Ao certo, portanto, fica descabida a totalidade do masculino e é cabida a feminilidade das sujeitas mulheres-pesquisadoras contra o imperialismo do sexo masculino nas Academias.
} 


\section{OO DEVIR EDUCAÇÃO}

ISSN: 2526-849X

suas respectivas produções e, igualmente, suplantar a noção ainda presente de que a ArteEducação é uma única abordagem/proposta.

Dessa forma é possível desobedecer epistemicamente, já que é desejado apresentar um olhar outro para os conceitos exibidos e de como eles estão postos, assim como as relações no ensino de Arte. Diz-se isso porque são conceitos que estão estabelecidos por uma colonialidade do saber, ou seja, pela modernidade, instaurados numa ideia eurocêntrica do que é Arte, Cultura, Conhecimento e Educação, trazendo sempre as experiências da autora com a mediação cultural, assim como com o ensino de Arte.

A outra pesquisa se inscreve sobre discussões de corpo, gênero e o papel da mulher dentro da Disciplina Ciências sob uma perspectiva outra que elucide discussões sobre o ocultamento de mulheres que perpassa desde imagens em livros didáticos e até mesmo no discurso da ciência moderno.

É neste sentido de (re)existência que nos propomos enquanto pesquisadoras a apresentar argumentos a partir de nosso lugar de fala e de resultados de nossas produções de conhecimentos para pensar ciências de modo outro como apresenta Mignolo (2010). Para ele a perspectiva descolonial é uma maneira outra de produzir que são sustentadas pela geo e corpo-política que se comprometem com os processos de descolonizar estes conhecimentos/saberes. Uma proposta outra que certamente é transontológica na perspectiva de Enrique Dussel (1982).

Os referidos projetos de pesquisa foram apresentados em determinada disciplina do programa de Pós-graduação, que também nos foi material e motivação para a escrita deste trabalho. Durante as apresentações muitas questões surgiram nos comentários e contribuições dos colegas que deveriam ler nossos projetos e responder a um modelo de análise durante as leituras, e então apresentar pessoalmente suas contribuições e/ou observações a respeito dos projetos.

Ali foi introduzida a corpo-política do conhecimento complementar da geopolítica. Além disso, esses dois conceitos, que sublinham a descolonialidade de conhecer, pensar, sentir e acreditar, são confrontados com a colonialidade de saber, pensar, sentir e acreditar que são a teopolitica e a egopolítica (poderíamos pensar que a biopolítica não passa de uma manifestação da egopolítica). (MIGNOLO, 2015, p. 115). (Tradução livre nossa). 
Após a apresentação do primeiro projeto de pesquisa foi necessário que nosso orientador fizesse uma extensa fala acerca da perspectiva descolonial, tendo em vista os questionamentos e dúvidas que surgiram durante as falas dos colegas. Deparamo-nos com mais um motivo para que a descolonialidade seja apresentada nos programas de pósgraduação como opção, fazendo parte da formação e constituição desses sujeitos inseridos na Academia. Pois se a apresentação da perspectiva descolonial tivesse se dado anteriormente, não seria necessária a fala do professor. Dizemos isso, pois as demais pesquisas das perspectivas que foram apresentadas no programa (positivismo, marxismo, fenomenologia) não precisaram dessa apresentação e justificativa durante as apresentações dos projetos, haja vista que elas já eram conhecidas pelos participantes do programa (demais discentes e docentes).

Dentro dos questionamentos apresentados aos nossos projetos, alguns foram acerca do prazo de qualificação que era menor com relação aos demais e ao cronograma previamente exposto e orientado a ser seguido pelo programa. Entretanto nossa proposta era de qualificar e defender antes do prazo, e assim, o fizemos, qualificamos no mesmo ano de ingressas, um marco para nosso Programa de Pós Graduação e um marco para formas outras de realizar pesquisas como a descolonial.

Outro questionamento feito foi quanto a pesquisa que deseja desenvolver a ideia de Arte-mediação, quando um integrante do programa argumentou que o desenvolvimento de uma ideia conceitual só poderia se dar em um projeto de Doutorado. Baseado em quê um colega diz isso? A partir de que perspectiva não é possível? Onde diz que não nos é possível realizar o desenvolvimento de uma ideia no Mestrado? Será por ser uma mulher? Será pelo lugar de fala da autora? Será pela estatura da autora? (Como também fora mencionado durante as falas dos colegas do programa). A Uni-versidade e a ciência, junto ao discurso de poder impregnado já nos próprios acadêmicos, questionam a possibilidade de outros saberes na Academia, como afirma Bessa-Oliveira (2019, p. 75):

A ciência é constituída como soberana e mantém-se ainda nas Universidades da atualidade, sem pluralidades de saberes, sem pluridiversidade como imaginação possível, porque esta instituição de ensino ainda está, quanto muito, sob a égide da transdisciplinaridade, do diálogo monodisciplinar do saber e de multiplicidade de disciplinas modernas, 


\section{OD DEVIR EDUCAÇÃO \\ ISSN: 2526-849X}

desqualificando, ou mesmo impedindo a entrada de outros saberes em seu recinto de conhecimento.

Trazer a proposta de desenvolvimento de uma ideia que considera também as experiências das autoras é um desafio à rigidez das disciplinas e dos modos de pensar ainda muito presentes na Academia, seja pelos docentes ou pelos discentes (MALDONADOTORRES, 2016). Mas somente dentro da pesquisa acadêmica, ainda que nos moldes da modernidade/colonialidade como são estruturadas as instituições de ensino é que poderemos provocar olhares outros para a pesquisa acadêmica, desobedecendo epistemicamente de maneira perseverante, (re)verificando ainda a noção de que penso (hegemonicamente), logo existo. "Enfim, a universidade e o museu são duas instituições chaves sobre as quais se fundou e se mantém a colonialidade do saber e da subjetividade." (MIGNOLO, apud LORCA, 2014, p. 2). Pior, a Uni-versidade se mantém, mais ainda nos lugares ao Sul (onde imperam machos, brancos de classe alta que se sentem detentores do poder porque carregam nas cinturas um 44 ou porque dominam o conhecimento acadêmico moderno) sob a égide de silenciar, aprisionar, desqualificar corpos estranhos (especialmente femininos) às disciplinas de professores que ocupam o lugar que mais deveria ser o do privilegio às diferenças: as salas de aula.

\section{Considerações finais: Sou (biogeohistoricamente), logo existo!}

Propormos epistemologias outras e práticas outras para o âmbito educacional, em busca de partirmos do princípio de (re)escrever, (re)pensar, (re)fazer e (re)significar a nossa história e a nossa cultura até para nós mesmos, fazendo reverberar a nossa voz enquanto sujeitos subalternizados, para transpor as fronteiras da marginalização. E salientamos, os (re) aqui grafados em nada têm dos sentidos das reopções da modernidade insistidas ainda hoje pela pós-modernidade. Quando falamos em re-alguma coisa, estamos argumentando da necessária opção outra como contramétodo (moderno e pós-moderno) a tudo já posto e imposto nas salas de aula com e por meio de métodos. 


\section{OO DEVIR EDUCAÇÃO}

ISSN: 2526-849X

Tratamos aqui de um "método" contramoderno, uma opção descolonial que vem a partir desse lugar, do lugar onde vivo e não sobre algum lugar (BESSA-OLIVEIRA, 2017). Nós como pesquisadoras de um Programa de Pós-Graduação, temos o privilégio de poder escrever nossa dissertação a partir do lugar onde vivenciamos a nossa história. A partir do nosso lócus. E infelizmente a ciência moderna não é capaz de compreender essas mudanças, onde seja possível ao subalterno ter lugar e vez na pesquisa acadêmica.

Como parte desta desconstrução do pensamento hegemonicamente imposto, temos como referência três temas de dissertação, aqui já apresentados, que trazem uma proposta epistemológica outra das autoras deste artigo. Igualmente, se já foram temas abordados na atual Uni-versidade, é importante dizer que estamos privilegiando nas pesquisas uma abordagem pela pluri-versidade de opções de produção de conhecimentos.

É neste sentido que a perspectiva descolonial sinaliza modos outros de (re)pensar acerca das construções intelectuais da humanidade rompendo com a dicotomia imposta pelo estereótipo homogeneizador eurocêntrico que no campo científico constitui-se na figura do homem branco, de classe média, cristão, fálico, dominante de idiomas europeus. Um corpo que assim estabeleceu-se como "adequado" e em razão disto superior aos "outros": logo, e entende-se como 'outros' os sujeitos que sejam mulheres, homens/mulheres negros e/ou indígenas, entre outras diferenças constatadas mediante ao padrão estabelecido. Assim, sujeitos culturais são todos "os outros" que acabam sendo ocultados inicialmente pelos discursos e imagens que, com o passar do tempo e com sua reincidência, legitimam tal ação e reforçam suas práticas excludentes.

Prioritariamente, nossas pesquisas privilegiam a diferença colonial, aquela que emergiu com os processos de colonização a partir da instauração do projeto moderno europeu como única forma de reconhecer o mundo ocidental e até a chamada parte do Oriente. Pois, ainda que chegada a chamada pós-modernidade, até mesmo a biopolítica foucaultiana alcançou o seu limite máximo em promover a quebra do mesmo paradigma trazido até ali pela modernidade. Logo, o pensamento descolonial é o desprender-se desse paradigma como única alternativa aos corpos que até então são subjulgados à marginalidade do pensamento moderno europeu do século XVI ou “aceitos" pelo projeto de globalização estadunidense imperante a partir do século XX.

Neste sentido de (re)existência é que enquanto pesquisadoras/es "nós, anthropos, que habitamos e pensamos nas fronteiras, estamos no caminho e em processo do desprendimento 
e para nos desprender precisamos ser epistemologicamente desobedientes" (MIGNOLO, 2017, p. 20). Somos desobedientes epistemologicamente quando há uma organização tentando impor como devemos falar ou pesquisar enquanto nós, convictas do lugar onde somos, sabemos e sentimos, ou seja, de um lugar fronteiriço, insistimos em seguir o caminho de descolonização. Mesmo que às vezes precisemos nos adaptar em determinadas situações para sermos "aceitas", é preciso resistir e apresentar um aporte teórico outro capaz de comprovar sua seriedade com o fazer-ser científico, um modo contramoderno.

Na prática entendemos que as disciplinas continuam sendo muito estanques e fechadas em grades específicas na Academia, mas isso não pode se constituir como indulgência para justificar o despreparo teórico e crítico dos intelectuais nos dias de hoje. Haja vista que o/a professor/a que não exerce um olhar, uma visão transcultural, sobre a disciplina que atua, presta um desserviço à educação no mundo atual. A perspectiva disciplinar e, por extensão, o discurso acadêmico, acreditam haver produção do conhecimento independente do desejo e das circunstâncias que constituem o sujeito como sujeito (NOLASCO, 2010, p. 42).

Entendemos também na esteira de Mignolo que dificilmente as universidades descolonizarão o saber, que essa proposição só poderá partir do corpo docente e discente. Walter Mignolo em determinada entrevista já citada aqui consegue ilustrar em detalhes o que apresentamos e entendemos, que deixam de ser necessários os comentários, preferimos apenas trazê-la para que o leitor tenha a experiência com a fala do autor:

É difícil pensar hoje que os dirigentes universitários em qualquer parte do mundo se proponham descolonizar o saber. Estes projetos provêm do corpo docente e discente, não da administração. Seria semelhante a esperar que o Estado inicie projetos de descolonização. [...] Os Estados estão atrelados às corporações e aos bancos. A administração universitária pode apoiar, em certos momentos, algumas iniciativas, mas não lhe é possível iniciar estes projetos. No dia em que as universidades públicas ou privadas gerirem a descolonização pedagógica, será porque os processos de descolonização que percebemos na sociedade política já contribuíram para uma mudança radical e para a dissolução da matriz colonial de poder. No momento, a descolonialidade é uma visão e uma orientação que coexiste e coexistirá em tensão com outras visões e sistemas de ideias (o liberalismo, o neoliberalismo, o marxismo, o cristianismo, o confucionismo, o islamismo), assim como com orientações e visões disciplinares (ciências humanas e 


\section{OD DEVIR EDUCAÇÃO \\ ISSN: 2526-849X}

naturais, escolas profissionais, etc.). A descolonialidade é uma opção entre outras (MIGNOLO, apud LORCA, 2014, p. 2).

Como pesquisadoras entendemos que as pesquisas precisam nos atravessar, precisam permear nossas práticas, precisam nos deslocar e nos remeter a lugares outros que não os periféricos sob lócus do centro, ou ainda imparcial e neutro imposto pela ciência moderna. E apresentamos como alternativa que esses modos outros não precisem ser tolerados, mas sim sejam respeitados, deslumbrados, conhecidos e considerados.

Estudos interdisciplinares na academia podem usar várias disciplinas para entender uma área ou problema e são questionados por não apresentar um método específico. "Como o método tem sido a marca definidora da racionalidade científica, a aparente ausência do mesmo faz com que os espaços interdisciplinares sejam concebidos como espaços menos racionais e rigorosos que os fornecidos pelas disciplinas" (MALDONADO-TORRES, 2016, p. 75).

Logo, esta descolonização epistêmica perpassa pelo modo de um caráter científico que proponha a se inscrever de modos outros, pois as disciplinas acadêmicas estão ainda muito atreladas à universidade ocidental moderna. "A universidade ocidental, com suas disciplinas e ramos do conhecimento, é uma instituição com transformações relativamente lentas e baseia sua legitimidade em processos históricos de alta envergadura e longa duração" (MALDONADO-TORRES, 2016, p. 76).

É constante a segregação de conhecimentos que perpassa por um corpo cartesiano, legítimo, universal e, por esta razão, válido. Tudo aquilo que difere e contrapõe ao discurso da ciência moderna é um desafio, um afrontamento, portanto a ciência moderna precisa se posicionar contra e demonstrar, de alguma forma, a invalidez do que difere para se reafirmar, ou seja, valoriza-se em detrimento de outra forma de pensar. A ciência, as disciplinas acadêmicas questionam a relevância e subjetividade da perspectiva descolonial pelas áreas de enfoque pesquisadas, os problemas e também pelos/as pesquisadores/as e estudantes de tal espaço de pesquisa e de produção de conhecimento.

É preciso problematizar o sistema cartesiano que estabelece hierarquias de conhecimentos e isso torna urgente a ruptura das demarcações da colonialidade de nossos corpos e pesquisas para um fazer científico contramoderno que conseguem introduzir modos 
outros de compreensão de mundo atravessados por uma ação onde os sujeitos-pesquisadores se percebam e realizem pesquisas com sentidos/significados em e para seu meio sociocultural.

Para pensar em uma produção acadêmica de modo descolonial é essencial um compromisso das pesquisadoras/docentes de experienciar o fazer científico em seus corpos e pesquisas que como aponta Paulo Freire (2002, p. 14) "seja tão fundamental conhecer o conhecimento existente, quanto o saber que estamos abertos e aptos a produção do conhecimento ainda não existente". E aqui queremos agregar a ideia de não apenas produzir e estar abertos a conhecimentos/saberes novos, mas em comprometer-se igualmente em elucidar os que foram ignorados, desconsiderados e excluídos pelo pensamento moderno e o modo cartesiano operante que mutilou e fragmentou os sujeitos, seus corpos e suas produções.

De modo que seja possível considerar e validar os processos outros dos sujeitos, suas escritas e pesquisas a partir de seu lugar de fala, mesmo que este gere desconforto por não estar hegemonicamente inscrito. Mesmo que des-conhecido! Afinal a máxima do "penso, logo existo" é para todos/as aqueles/as que comprometidos com aportes teóricos decidem produzir, re(significar), (re)pensar, (re)construir saberes/conhecimentos. Logo, a hegemonia carrega as marcas da neutralidade, impessoalidade e universalidade que se constitui enquanto um adendo da ciência moderna que mais contribuiu para exclusão de produções do que para expansão de conhecimentos/saberes. Por isso a desruptura com o hegemonicamente imposto é um compromisso para um caminho descolonial tão necessário para um desobedecer epistemológico que vislumbre aos sujeitos enquanto produtores/as de conhecimentos/saberes liberdade em suas salas, em seus artigos, produções acadêmicas e assim um fazer cientifico mais empático e menos excludente.

\section{REFERÊNCIAS}

BESSA-OLIVEIRA, Marcos Antônio. Educação, Tecnocolonialidade, Docência Remota \& a Covid-19. Campo Grande, MS: Life Editora, 2020.

BESSA-OLIVEIRA, Marcos Antônio. ARTE, CULTURA E EDUCAÇÃO NA FORMAÇÃO DOCENTE COM PERSPECTIVAS DOS ESTUDOS DE CULTURAS. Movimento-revista de educação, Submissões, n. 11, p. 100-136, nov. 2019. ISSN 23593296. Disponível em: 〈https://periodicos.uff.br/revistamovimento/article/view/32877>. Acesso em: 19 oct. 2020. doi:https://doi.org/10.22409/mov.v0i11.32877. 
BESSA-OLIVEIRA, Marcos Antônio. Pedagogias da diversalidade. Cadernos de Estudos Culturais, Campo Grande, MS, v. 1, p. 61-86, jan./jun. 2019. Disponível em: https://periodicos.ufms.br/index.php/cadec/article/view/9691. Acesso em: 19 out. 2020.

BESSA-OLIVEIRA, Marcos Antônio. "Para experimentar, formar, praticar, caminhar é preciso antes ser, sentir, saber bio-geo-grafias no ensino de artes". In: XXVII Congresso Nacional da Federação de Arte/Educadores do Brasil ; V Congresso Internacional dos Arte/Educadores ; II Seminário de Cultura e Educação de Mato Grosso do Sul [recurso eletrônico] : anais / comissão organizadora, Caciano Silva Lima, Vera Lúcia Penzo Fernandes. - Campo Grande, MS: Federação de Arte/Educadores do Brasil, 2017, p. 240-256. Disponível em: https://faeb.com.br/admin/shared/midias/1510688060.pdf. Acesso 22 jun. 2018.

DUSSEL, Enrique D.. Método para uma filosofia da libertação: superação analética da dialética hegeliana. Tradução Jandir João Zanotelli. São Paulo: Edições Loyola, 1986.

DUSSEL, Enrique D.. Filosofia na América Latina. Filosofia da libertação. Tradução Luiz João Gaio. São Paulo: Edições Loyola; Piracicaba, SP: Editora UNIMEP, 1982.

FREIRE, Paulo. Pedagogia da Autonomia: Saberes necessários a Prática Educativa. São Paulo: Paz e Terra, 2002.

LORCA, Javier. O controle dos corpos e dos saberes. Entrevista com Walter Mignolo. Tradução: André Langer. In: Página/12, 08 de setembro de 2014, p. 1-3. Disponível em: http://www.ihu.unisinos.br/noticias/533148ocontroledoscorposedossaberesentrevistacomwalt ermignolo?tmpl=component\&amp;print=1\&amp;page=. Acesso em: 29 abr. 2016.

MALDONADO-TORRES, Nelson. Transdisciplinaridade e decolonialidade. In: Sociedade e Estado - Volume 31, número 1, Janeiro/Abril 2016. Disponível em: <http://www.scielo.br/pdf/se/v31n1/0102-6992-se-31-01-00075.pdf>. Acesso em: $05 / 08 / 2019$.

MIGNOLO, Walter D.. Habitar la frontera: Sentir y pensar la descolonialidad (Antología, 1999-2014). Francisco Carballo y Luis Alfonso Herrera Robles (Prólogo y selección). CIDOB - Center For International Affairs, Barcelona; colaboración de Universidad Autónoma de Ciudad Juárez (UACJ); Ciudad Juárez, Chihuahua, México, 2015.

MIGINOLO, Walter D.. Desafios decoloniais hoje. Tradução de Marcos de Jesus Oliveira. Revista Epistemologias do Sul. Foz do Iguaçu, PR. V.1, n.1, 2017, p. 12-32. Disponível em: https://revistas.unila.edu.br/epistemologiasdosul/article/download/772/645. Acesso em: 27 fev. 2020.

MIGNOLO, Walter. Desobediência epistémica: Retórica de la modernidad, lógica de la colonialidad, y gramática de la descolonialidad. Buenos Aires: Ediciones del Signo, 2010.

MIGNOLO, Walter D.. Histórias locais/ Projetos globais: colonialidade, saberes subalternos e pensamento liminar. Trad. Solange Ribeiro de Oliveira. Belo Horizonte: Editora UFMG, 2003. (Humanitas). 
SOUZA, Eneida Maria de. Crítica cult. Belo Horizonte: Editora UFMG, 2002. (Humanitas).

NOLASCO, Edgar Cézar Nolasco. BabeLocal: lugares das miúdas culturas. Campo Grande, MS, Life Editora, 2010.

NOLASCO, Edgar Cézar. Descolonizando a pesquisa acadêmica: uma teorização sem disciplinas. Cadernos de Estudos Culturais: Tendências Artísticas do Século XXI, v. 1, n. 19, jan./jun., 2018, p. 9-21. Disponível em: https://periodicos.ufms.br/index.php/cadec/article/view/7725. Acesso em: 20 abr. 2020.

QUIJANO, Aníbal. Aníbal Quijano: ensayos en torno a la colonialidad del poder. Compilado por Walter Mignolo. 1a ed.. Ciudad Autónoma de Buenos Aires: Del Signo, 2019. (El desprendimiento / Mignolo, Walter).

SANTOS, Boaventura de Sousa. Corpos, conhecimentos e corazonar. In: SANTOS, Boaventura de Sousa, O fim do império cognitivo: a afirmação das epistemologias do Sul. $1^{\text {a }}$ ed. 1. reimp. - Belo Horizonte: Autêntica Editora, 2019, p. 135-157.

SKLIAR, Carlos. Introdução - A escrita na escrita: Derrida e Educação. In: SKLIAR, Carlos. (Org.). Derrida \& a Educação. Belo Horizonte: Autêntica Editora, 2005, p. 9-34.

Recebido em: 01/07/2020

Aprovado em: 20/08/2020 